\title{
Hepatobiliary Transport of Glutathione and Glutathione Conjugate in Rats with Hereditary Hyperbilirubinemia
}

Ronald P. J. Oude Elferink, Roel Ottenhoff, Wil Liefting, Jan de Haan, ${ }^{\star}$ and Peter L. M. Jansen

Divisions of Gastrointestinal and Liver Diseases and *Experimental Medicine, Academic Medical Center, 1105 AZ Amsterdam, The Netherlands

\begin{abstract}
$\mathrm{TR}^{-}$mutant rats have an autosomal recessive mutation that is expressed as a severely impaired hepatobiliary secretion of organic anions like bilirubin-(di)glucuronide and dibromosulphthalein (DBSP). In this paper, the hepatobiliary transport of glutathione and a glutathione conjugate was studied in normal Wistar rats and $\mathbf{T R}^{-}$rats.

It was shown that glutathione is virtually absent from the bile of $\mathrm{TR}^{-}$rats. In the isolated, perfused liver the secretion of glutathione and the glutathione conjugate, dinitrophenyl-glutathione (GS-DNP), from hepatocyte to bile is severely impaired, whereas the sinusoidal secretion from liver to blood is not affected.

The secretion of GS-DNP was also studied in isolated hepatocytes. The secretion of GS-DNP from cells isolated from $\mathrm{TR}^{-}$rat liver was significantly slower than from normal hepatocytes. Efflux of GS-DNP was a saturable process with respect to intracellular GS-DNP concentration: $V_{\max }$ and $K_{\mathrm{m}}$ for efflux from $\mathrm{TR}^{-}$cells was $498 \mathrm{nmol} / \mathrm{min} \cdot \mathrm{g}$ dry wt and 3.3 $\mathrm{mM}$, respectively, as compared with $1514 \mathrm{nmol} / \mathrm{min} \cdot \mathrm{g}$ dry wt and $0.92 \mathrm{mM}$ in normal hepatocytes.

These results suggest that the canalicular transport system for glutathione and glutathione conjugates is severely impaired in TR $^{-}$rats, whereas sinusoidal efflux is unaffected. Because the defect also comes to expression in isolated hepatocytes, efflux of GS-DNP from normal hepatocytes must predominantly be mediated by the canalicular transport mechanism, which is deficient in $\mathrm{TR}^{-}$rats.
\end{abstract}

\section{Introduction}

Organic anions like bilirubin are efficiently cleared by the liver and secreted into bile. In the human Dubin Johnson syndrome this process is impaired, probably due to a canalicular secretion defect (1). Recently we have described a rat strain with inherited, conjugated hyperbilirubinemia ( $\mathrm{TR}^{-}$mutant rat), which resembles the human Dubin Johnson syndrome in many respects (2). The biliary secretion of organic anions like

Part of this study has been presented in a preliminary form at the Annual Meeting of the American Association for the Study of Liver Diseases, Chicago, IL, 27-28 October, 1987.

Address reprint requests to Dr. Ronald P. J. Oude Elferink, Division of Gastrointestinal and Liver Diseases, Academic Medical Center, Meibergdreef 9, $1105 \mathrm{AZ}$ Amsterdam, The Netherlands. 1989.

Received for publication 15 April 1988 and in revised form 4 April

J. Clin. Invest.

(C) The American Society for Clinical Investigation, Inc 0021-9738/89/08/0476/08 $\$ 2.00$

Volume 84, August 1989, 476-483 conjugated bilirubin (3), dibromosulphthalein $(\mathrm{DBSP})^{1}(2,4)$, and sulfated and glucuronidated bile acids (5) is strongly reduced in this rat, whereas the secretion of taurocholate and cholate is normal (4). The $\mathrm{TR}^{-}$rat may provide valuable information for the explanation of inherited and acquired biliary secretion disorders. In addition, a comparison of secretion processes in the $\mathrm{TR}^{-}$rat and the normal rat may help to unravel the molecular mechanism of canalicular organic anion transport.

Within the group of compounds that are poorly secreted into bile of the $\mathrm{TR}^{-}$rat are also glutathione-conjugates like bromosulphthalein (BSP)-glutathione. It has been shown by different groups (6-9) that glutathione itself is also secreted into bile of the rat. The reported biliary concentrations of glutathione vary from 1.8 to $4 \mathrm{mM}(6-8)$, but these values represent underestimations. Ballatori et al. (6) have demonstrated that as much as $50 \%$ of the biliary glutathione can be hydrolyzed by gamma-glutamyltranspeptidase (gamma-GT). Gregus et al. (9) recently reported a fivefold increase in the biliary glutathione concentration after inhibition of gammaGT. Inoue et al. (10) have suggested from experiments with isolated canalicular plasma membrane vesicles, that (oxidized and reduced) glutathione and the conjugate dinitrophenyl-glutathione (GS-DNP) are transported via the same carrier system. However, competition between reduced glutathione (GSH) and oxidized glutathione (GSSG) or GS-DNP has never been observed in vivo and in experiments with isolated, perfused livers. On the other hand, a clear competition between GSSG and GS-DNP has been demonstrated in the isolated, perfused rat liver (11). To investigate the nature of this transport system we have measured transport of GSH, GSSG, and GS-DNP in Wistar and $\mathrm{TR}^{-}$rats.

\section{Methods}

\section{Chemicals}

1-Chloro-2,4-dinitrobenzene (CDNB) was obtained from Janssen Life Sciences Products (Beerse, Belgium). Glutathione and glutathione reductase (from yeast) were from Boehringer (Mannheim, FRG) and gamma-glutamyl-p-nitroanilide from Merck (Darmstadt, FRG). ${ }^{14} \mathrm{C}$ labeled 1-chloro-2,4-dinitrobenzene (specific radioactivity: $5.87 \mathrm{mCi}$ / mmol) and tritiated water were obtained from Amersham International (Houten, The Netherlands). $\left[{ }^{14} \mathrm{C}\right]$ Methoxy-inulin was from New England Nuclear, Boston, MA. All chemicals were of analytical quality.

\section{Animals}

Normal male Wistar rats, weighing $\sim 300-350 \mathrm{~g}$, were obtained from Harlan-CPB (Zeist, The Netherlands). Male TR $^{-}$mutant, GT $^{-} \mathbf{T R}^{+}$

1. Abbreviations used in this paper: BSP, tetrabromosulphthalein; CDNB, 1-chloro-2,4-dinitrobenzene; DBSP, dibromosulphthalein; GS-DNP, dinitrophenyl glutathione; GSSG, oxidized glutathione; GSH, reduced glutathione; gamma-GT, gamma-glutamyltranspeptidase. 
(Gunn), and $\mathrm{GT}^{-} \mathrm{TR}^{-}$double mutant rats of the same weight came from our own breeding colonies. These strains are characterized in references $2-4$. All experiments were carried out with ad lib. fed rats.

\section{Experimental procedures}

Intact rats. Rats were anesthetized with pentobarbital (Nembutal, 50 $\mathrm{mg} / \mathrm{kg}$ i.p.) and the common bile duct was cannulated using $0.9-\mathrm{mm}$ tubing. The rats were placed on thermostatted heating pads to maintain their body temperature at $37^{\circ} \mathrm{C}$. CDNB was dissolved in olive oil $(10 \mu \mathrm{mol} / 50 \mu \mathrm{l})$ and injected intravenously (through the portal vein). Bile samples were acidified immediately during collection by immersion of the cannula in $10 \%$ perchloric acid (final concentration $3.5 \%$ ) and placed on ice. For determination of glutathione in liver tissue, the livers were perfused with Krebs buffer/bicarbonate for $5 \mathrm{~min}$, excised, and freeze clamped in liquid nitrogen. The freeze-clamped tissue was homogenized and immediately acidified with perchloric acid to a final concentration of $3.5 \%$. After centrifugation of the bile and liver samples the supernatants were neutralized with $3 \mathrm{M}$ potassium phosphate and frozen to precipitate perchlorate completely. After thawing and centrifugation, the supernatants were analyzed. The concentration of GS-DNP was determined by measurement of the absorption at 335 $\mathrm{nm}$, using a molar extinction coefficient for GS-DNP of $9.6 \times 10^{3}$ $\mathrm{cm}^{-1} \cdot \mathrm{mol}^{-1}(12)$. To determine biliary metabolites of CDNB, $\left[{ }^{14} \mathrm{C}\right] \mathrm{CDNB}$ was diluted with unlabeled CDNB and injected intravenously as described above. Biliary $\left[{ }^{14} \mathrm{C}\right] \mathrm{CDNB}$ metabolites were analysed by thin layer chromatography as described by Awasthi et al. (13). Samples were mixed with 2 vol 1-propanol, centrifuged and the supernatant was applied to thin-layer chromatography plates (Kieselgel 60; Merck). The plates were developed with 1-propanol/water (7:3) and dried. 0.5-cm lanes were scraped off, added to scintillation fluid (Instagel; Packard Instruments, Downers Grove, IL), and counted. In this procedure GS-DNP (fractional retention $\left[R_{\mathrm{f}}\right]=0.38$ ) was separated from $\left[{ }^{14} \mathrm{C}\right] \mathrm{CDNB}\left(R_{\mathrm{f}}=0.59\right)$, cysteinyl-DNP $\left(R_{\mathrm{f}}=0.50\right)$, and glycinecysteinyl-DNP $\left(R_{\mathrm{f}}=0.53\right)$.

Isolated perfused liver. Rats were anesthetized and cannulated in the common bile duct as described above. Subsequently, the liver was isolated and installed in a perfusion system exactly as described in reference 14. The weight of the livers varied from 12 to $18 \mathrm{~g}$. Perfusion was carried out in an orthograde recirculating fashion with Krebs buffer/bicarbonate medium containing $0.5 \%$ BSA. The Krebs solution that we used consisted of $120 \mathrm{mM} \mathrm{NaCl}, 24 \mathrm{mM} \mathrm{NaHCO}, 4.8 \mathrm{mM}$ $\mathrm{KCl}, 1.2 \mathrm{mM} \mathrm{KH}_{2} \mathrm{PO}_{4}, 1.2 \mathrm{mM} \mathrm{MgSO}_{4}$, and $1.3 \mathrm{mM} \mathrm{CaCl}_{2}$. The medium was gassed with carbogene $\left(\mathrm{O}_{2} / \mathrm{CO}_{2}=95: 5\right)$ in an oxygenator. Perfusate flow was between 40 and $60 \mathrm{ml} / \mathrm{min}$ and the hydrostatic pressure was $18 \mathrm{~cm}$ (water). The perfusion chamber was humidified and kept at $37^{\circ} \mathrm{C}$ by a thermostatically regulated heating fan. Bile samples were collected as described above. Perfusate samples were taken from the caval (outflow) cannula and immediately acidified with perchloric acid to a final concentration of $3.5 \%$. Further processing was exactly as described for bile samples. In experiments in which glutathione secretion was measured, the perfusion lasted $30 \mathrm{~min}$. In the other experiments, CDNB was completely dissolved in the medium before perfusion and in these experiments perfusion was carried out for $75 \mathrm{~min}$.

Isolated hepatocytes. Hepatocytes were isolated by the method of Berry and Friend (15), modified as described below. The abdomen of the rat was opened and the rat was heparinized $(500 \mathrm{IU} / \mathrm{kg}$ ) by intravenous injection. The portal vein was incised and a cannula (model G16; Braun, Melsungen, FRG) with perfusate running at $\sim 10 \mathrm{ml} / \mathrm{min}$ was inserted and secured with a ligature. The vena cava inferior was cut open and the liver was excised. The time from the insertion of the cannula until the liver had been freed was usually $\sim 2 \mathrm{~min}$. The perfusate consisted of $\mathrm{Krebs} / \mathrm{bicarbonate}$ without $\mathrm{Ca}^{2+}$ and with 10 mM Hepes, pH 7.4, and was gassed with carbogene. The liver was placed in a perfusion chamber and perfusion with $\mathrm{Ca}^{2+}$-free $\mathrm{Krebs} / \mathrm{bi}$ carbonate was carried out for $5 \mathrm{~min}$. Then the perfusate was changed for $\mathrm{Ca}^{2+}$-containing $\mathrm{Krebs} /$ bicarbonate which contained $20 \mathrm{mg} / 100$ $\mathrm{ml}$ collagenase (from Clostridium histolyticum, $0.44 \mathrm{U} / \mathrm{mg}$ lyophyli- sate, Sigma Chemical Co.). Collagenase treatment lasted $8 \mathrm{~min}$. At the end of the perfusion, the liver was placed in a large Petri dish, the capsula was cut and the cells were gently dispersed with a coarse comb. The cells were filtered through a nylon gauze and the filtrate was centrifuged for 2 min at $50 \mathrm{~g}$. Subsequently the cells were washed three times by resuspension in cold Krebs/bicarbonate with Hepes containing $0.2 \% \mathrm{BSA}$ and centrifugation for $2 \mathrm{~min}$ at $50 \mathrm{~g}$. Finally, the viability of the cells was checked by trypan blue exclusion and this was always $>90 \%$. The cells were kept on ice until use within $15 \mathrm{~min}$.

During the experiments, the cells were incubated in Krebs/bicarbonate containing $10 \mathrm{mM}$ Hepes, $\mathrm{pH} 7.4,1 \mathrm{mM}$ octanoate, $10 \mathrm{mM}$ glucose, and $0.5 \%$ BSA (essentially free of fatty acids). Incubation was carried out in $25-\mathrm{ml}$ flasks in a gently shaken waterbath $\left(37^{\circ} \mathrm{C}\right)$ under constant carbogene gassing. The incubation volume was $6 \mathrm{ml}$. Cells were added to a concentration of $10 \mathrm{mg} / \mathrm{ml}$ dry weight and preincubated for $15 \mathrm{~min}$ at $37^{\circ} \mathrm{C}$. CDNB, dissolved in DMSO and diluted in Krebs/BSA, was added (the final DMSO concentration was $0.03 \%$ of the total incubation volume). After taking a sample of the suspension, cells were separated from the medium by centrifugation of an $0.6-\mathrm{ml}$ sample through a 0.6-ml layer of ice-cold silicone oil (Wacker AR 200:AR20 $=3: 2$, Wacker Chemie GmbH, München, FRG) into a $0.2-\mathrm{ml}$ layer of ice-cold $10 \%$ perchloric acid. The supernatant of this centrifugation step was acidified with perchloric acid (10\% final concentration) and kept on ice. Denaturated proteins were removed by centrifugation. The cell pellet was homogenized and recentrifuged. Supernatants of the deproteinized medium were used for determination of GS-DNP concentrations as described above.

Initial GS-DNP secretion rates and kinetic parameters of secretion in hepatocytes were determined by adding $\left[{ }^{14} \mathrm{C}\right] \mathrm{CDNB}$ that was diluted to the indicated concentration with unlabeled CDNB. In this type of experiments samples were taken every $30 \mathrm{~s}$ from $30 \mathrm{~s}$ to $2.5 \mathrm{~min}$ after addition of CDNB. After centrifugation of the cells through silicone oil, a 100- $\mu$ l sample was taken from the supernatant, added to $10 \mathrm{ml}$ Instagel (Packard Instruments) and counted in a liquid scintillation counter. Within $<30 \mathrm{~s}$, uptake of CDNB was complete and during the experimental time interval the secretion of GS-DNP was linear both in control and mutant rats (analysis of the data with linear regression; $r$ $>0.99$ ). In samples taken at $30 \mathrm{~s}$ and $2.5 \mathrm{~min}$ after addition of CDNB, $\left[{ }^{14} \mathrm{C}\right] \mathrm{CDNB}$ metabolites were analyzed by thin-layer chromatography as described above.

Intracellular GS-DNP concentrations in millimolar were calculated as follows. The added amount of CDNB (which is completely converted to GS-DNP) in micromoles/gram dry wt was divided by the intracellular volume in milliliters/gram dry wt. The latter was determined as follows. Hepatocytes were incubated under identical conditions as for the determination of GS-DNP efflux but without labeled CDNB. $\left[{ }^{14} \mathrm{C}\right]$ Methoxy-inulin and $\left[{ }^{3} \mathrm{H}\right] \mathrm{H}_{2} \mathrm{O}$ were added to the cells and after $15 \mathrm{~min}$, the cells were centrifuged through oil as described above. ${ }^{3} \mathrm{H}$ and ${ }^{14} \mathrm{C}$ counts were determined in both cellular and medium fraction. The intracellular volume was calculated from the ${ }^{3} \mathrm{H}$ counts in the cellular fraction after correction for adhering water $\left(\left[{ }^{14} \mathrm{C}\right] \mathrm{meth}\right.$ oxy-inulin counts). The obtained intracellular volumes were $2.71 \pm 0.50 \mathrm{ml} / \mathrm{g}$ dry wt and $2.85 \pm 0.56 \mathrm{ml} / \mathrm{g}$ dry wt for $\mathrm{GT}^{-} \mathrm{TR}^{+}$and $\mathrm{GT}^{-} \mathrm{TR}^{-}$rats, respectively.

\section{Enzymatic determinations}

GSH was measured as described by Tietze et al. (16). GSSG was determined according to the procedure of Sacchetta (17). Measurements were carried out with internal and external standards of glutathione. Glutathione $S$-transferase was measured with CDNB as substrate as described in reference 18 and gamma-GT with gamma-glutamyl-p-nitroanilide as substrate as described in reference 19. Amino acid composition was determined on a standard amino acid analyzer after deproteination, as described above.

\section{Results}

Biliary secretion of glutathione and dinitrophenylglutathione in the intact rat. To study the hepatobiliary transport of a 
glutathione-conjugate, we have injected CDNB intravenously in normal Wistar rats and $\mathrm{TR}^{-}$mutants. CDNB is a hydrophobic compound that very rapidly enters the cell probably via simple diffusion (see below). After conjugation in the hepatocyte, the glutathione-conjugate GS-DNP, is efficiently secreted into bile (20). In the experiment shown in Fig. 1, rats were injected intravenously with CDNB $(3 \mu \mathrm{mol} / 100 \mathrm{~g})$ and bile samples were collected. During the time interval of the experiment, $84 \%$ of the injected dose was recovered in bile of the Wistar rat and $1.7 \%$ was recovered in bile of the $\mathrm{TR}^{-}$rat. Average bile flow during the experiment was $55.3 \mu \mathrm{l} / \mathrm{min} \cdot \mathrm{kg}$ in the Wistar rat and $37.0 \mu \mathrm{l} / \mathrm{min} \cdot \mathrm{kg}$ in the $\mathrm{TR}^{-}$rat. The peak GS-DNP secretion in the Wistar rat was $0.32 \mu \mathrm{mol} / \mathrm{min} \cdot \mathrm{kg}$ in the Wistar rat and $0.012 \mu \mathrm{mol} / \mathrm{min} \cdot \mathrm{kg}$ in the $\mathrm{TR}^{-}$rat. At higher concentrations of CDNB $(15 \mu \mathrm{mol} / 100 \mathrm{~g})$ than those used in this experiment, the secretion of GS-DNP had a choleretic effect in the Wistar rat but not in the $\mathrm{TR}^{-}$rat (results not shown). It is evident that biliary transport of GS-DNP in mutant $\mathrm{TR}^{-}$rats is significantly impaired (Fig. 1 shows a representative experiment from a set of four). To analyze the secreted metabolites of CDNB, we injected control and mutant rats with $\left[{ }^{14} \mathrm{C}\right] \mathrm{CDNB}$. It was found again that the $\mathrm{TR}^{-}$rat secretes only minor amounts of radioactivity into bile, in contrast to the normal rat, which secreted $>80 \%$ of the injected dose into bile. In fresh bile samples from the Wistar rat, only GS-DNP and no other metabolites of CDNB were found as judged by analysis of the bile samples by thin-layer chromatography. Due to the low amount of radioactivity in mutant rat bile, it was difficult to make a reliable analysis of the metabolites, but qualitatively, the chromatogram was identical to that of control bile.

Inoue et al. (10) have demonstrated that in isolated canalicular plasma membrane vesicles the transport of GS-DNP is carrier mediated and that oxidized and reduced glutathione inhibit the transport of GS-DNP. From these observations they suggested that glutathione and GS-DNP are transported via the same canalicular carrier system. We have measured glutathione levels in bile and liver tissue of normal and mutant rats. Table I shows that bile of Wistar rats contains a considerable amount of oxidized and reduced glutathione and that glutathione is practically absent from bile of $\mathrm{TR}^{-}$rats $(<0.006$ $\mathrm{mM})$. In contrast, liver tissue of mutant rats contains a signifi-

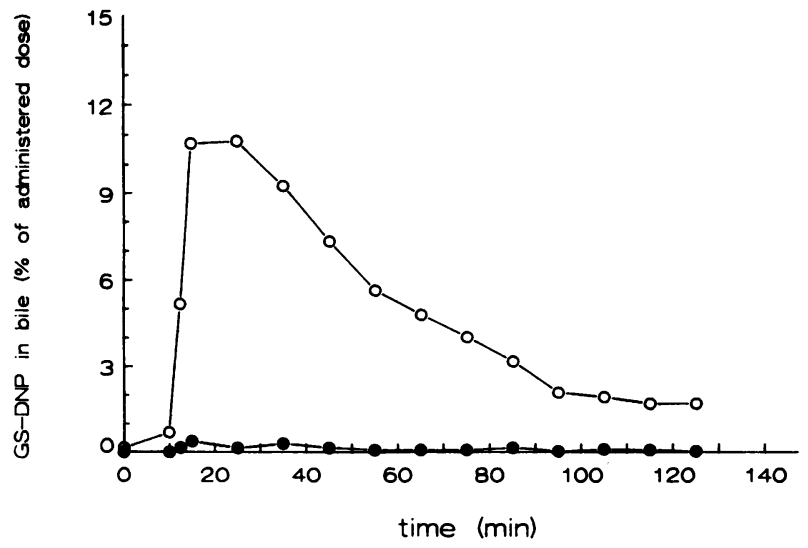

Figure 1. Biliary secretion of GS-DNP in normal and $\mathrm{TR}^{-}$mutant rats. Rats were injected with CDNB $(3 \mu \mathrm{mol} / 100 \mathrm{~g})$ after cannulation of the bile duct. Open symbols, Wistar rat; closed symbols, $\mathrm{TR}^{-}$rat. Bile samples were analyzed as described in Methods.
Table I. Glutathione Concentration in Liver and Bile from Normal and $T R^{-}$Rats

\begin{tabular}{lccc}
\hline & Wistar & TR $^{-}$mutant & $P$ \\
\hline Bile $($ mmol/liter $)(n=7)$ & & & \\
GSH & $2.26 \pm 0.94$ & $<0.006$ & $<0.01$ \\
GSSG & $0.92 \pm 0.28$ & ND & $<0.01$ \\
Liver $(\mu \mathrm{mol} / \mathrm{g})(n=3)$ & & & \\
GSH & $4.27 \pm 0.85$ & $10.46 \pm 1.15$ & $<0.01$ \\
GSSG & $0.26 \pm 0.03$ & $0.79 \pm 0.23$ & $<0.05$
\end{tabular}

ND, not detectable.

The first $150 \mu \mathrm{l}$ of bile collected after bile duct cannulation was denaturated immediately after collection as described in Methods. Liver was freeze clamped in liquid nitrogen immediately after isolation. The tissue was homogenized in $3.5 \%$ perchloric acid and the homogenate was centrifuged. The supernatant was further processed as described for bile. All concentrations are expressed as GSH equivalents \pm SD.

cantly higher glutathione concentration than that of the Wistar rat.

Gamma-GT in the bile canaliculi and ductuli hydrolyzes glutathione in bile $(21,22)$. To exclude the possibility that the difference in biliary glutathione concentration between normal and mutant rats is due to an elevated gamma-GT activity in $\mathrm{TR}^{-}$rats, the activity of this enzyme was measured in liver homogenates. The activity in Wistar rat and $\mathrm{TR}^{-}$rat liver was very similar: $0.058 \pm 0.014 \mu \mathrm{mol} / \mathrm{min} \cdot \mathrm{g}$ liver in the Wistar rat and $0.076 \pm 0.021 \mu \mathrm{mol} / \mathrm{min} \cdot \mathrm{g}$ liver in the $\mathrm{TR}^{-}$rat. To exclude increased metabolism of glutathione in bile from $\mathrm{TR}^{-}$rats as a cause of the absence of glutathione, we have also determined the free amino acid composition of bile from rats of both strains. Table II shows some striking differences in amino acid levels between normal and mutant bile. First, there is a more than fivefold lower concentration of glutamate in bile of mutant rats than in control rats. This difference is most probably

Table II. Amino Acid Analysis of Wistar and TR Mutant Bile

\begin{tabular}{lccc}
\hline & $\begin{array}{c}\text { Wistar } \\
(n=5)\end{array}$ & $\begin{array}{c}\mathrm{TR}^{-} \\
(n=5)\end{array}$ & $P$ \\
\hline \multicolumn{4}{c}{ mmol/liter }
\end{tabular}

$\begin{array}{lccc}\text { Taurine } & 0.091 \pm 0.032 & 0.081 \pm 0.041 & \text { NS } \\ \text { Threonine } & 0.126 \pm 0.015 & 0.046 \pm 0.024 & <0.001 \\ \text { Serine } & 0.190 \pm 0.045 & 0.106 \pm 0.012 & <0.01 \\ \text { Asparagine } & 0.045 \pm 0.029 & 0.014 \pm 0.005 & \text { NS } \\ \text { Glutamate } & 1.270 \pm 0.200 & 0.219 \pm 0.039 & <0.001 \\ \text { Glycine } & 0.765 \pm 0.197 & 0.376 \pm 0.034 & <0.01 \\ \text { Alanine } & 0.257 \pm 0.044 & 0.189 \pm 0.058 & \text { NS } \\ \text { Valine } & 0.378 \pm 0.300 & 0.073 \pm 0.017 & \text { NS } \\ \text { Isoleucine } & 0.135 \pm 0.067 & 0.026 \pm 0.036 & <0.05 \\ \text { Leucine } & 0.313 \pm 0.117 & 0.121 \pm 0.033 & <0.01 \\ \text { Tyrosine } & 0.091 \pm 0.044 & 0.013 \pm 0.013 & <0.01 \\ \text { Phenylalanine } & 0.142 \pm 0.036 & 0.051 \pm 0.020 & <0.01 \\ \text { Lysine } & 0.103 \pm 0.033 & 0.069 \pm 0.009 & \text { NS } \\ \text { Histidine } & 0.068 \pm 0.018 & 0.036 \pm 0.005 & <0.01\end{array}$

Amino acid analysis was carried out in five of the samples in which glutathione was measured (Table I). These samples consisted of the first $150 \mu \mathrm{l}$ bile that were collected after cannulation of the bile duct. 
derived from hydrolyzed glutathione (6) and confirms that the strong reduction in biliary glutathione concentration is due to a reduced secretion in the $\mathrm{TR}^{-}$rat and not to increased hydrolysis of glutathione in bile. The concentration of some other amino acids like threonine, leucine, isoleucine, tyrosine, and phenylalanine is also about two- to fivefold reduced. The biliary concentration of the uncharged molecule urea is similar in both rats $\left(6.8 \mathrm{mM}\right.$ and $7.3 \mathrm{mM}$ in Wistar and $\mathrm{TR}^{-}$rats, respectively).

Sinusoidal and canalicular secretion of glutathione and GS-DNP in the isolated perfused liver. We have investigated the secretion of glutathione in the isolated, perfused liver. In this system, it is possible to compare sinusoidal and canalicular efflux rates. Table III shows that in the isolated, perfused liver of the $\mathrm{TR}^{-}$rat, there is almost no biliary secretion of glutathione. In contrast, the rate of appearance of glutathione in the perfusate is similar in both rat strains, indicating that sinusoidal efflux of glutathione is not affected in the $\mathrm{TR}^{-}$rat. Bile flow in these experiments ranged from 0.6 to $1.1 \mu \mathrm{l} / \mathrm{min} \cdot \mathrm{g}$ liver in Wistar livers and from 0.15 to $0.33 \mu \mathrm{l} / \mathrm{min} \cdot \mathrm{g}$ liver in $\mathrm{TR}^{-}$ livers.

In addition to glutathione, the secretion of GS-DNP was also studied in the isolated perfused liver. Fig. 2 shows a representative experiment (from a set of three). In this experiment, $20 \mu \mathrm{mol}$ CDNB was added to the recirculating perfusate of either control (Fig. $2 A$ ) or $\mathrm{TR}^{-}$rat liver (Fig. $2 B$ ). No GSDNP was found in bile from the $\mathrm{TR}^{-}$liver. Average bile flow was $1.50 \mu \mathrm{l} / \mathrm{min} \cdot \mathrm{g}$ liver in the Wistar liver and $0.36 \mu \mathrm{l} / \mathrm{min} \cdot \mathrm{g}$ liver in the $\mathrm{TR}^{-}$liver. In the normal rat the amount of GSDNP secreted into bile within $70 \mathrm{~min}$ is sixfold higher than that secreted into the perfusate (Fig. $2 \mathrm{~A}$ ). It is also clear from Fig. 2 that the amount of GS-DNP secreted into the perfusate of the control liver is lower than that in the perfusate of the mutant liver. We propose that this is due to the fact that the intracellular concentration of GS-DNP in the control liver is lower because of the fast biliary secretion. To test this hypothesis and to compare sinusoidal efflux of GS-DNP in both rat strains more rigorously, we have carried out exactly the same experiment as in Fig. 2, with the difference that at the start of the experiment the bile duct was ligated. In this experiment the secretion of GS-DNP into the perfusate was similar in both types of liver, which confirms the fact that the secretion defect in the mutant liver is exclusively confined to the canalicular

Table III. Glutathione Secretion Rates in the Isolated, Perfused Liver of Wistar and $T R^{-}$Mutant Rats

\begin{tabular}{lcc}
\hline Secretion from liver to & \multicolumn{1}{c}{$\begin{array}{c}\text { Wistar } \\
(n=3)\end{array}$} & $\begin{array}{c}\mathrm{TR}^{-} \text {mutant } \\
(n=3)\end{array}$ \\
\hline & \multicolumn{2}{c}{ nmol/min $\cdot \mathrm{gliver}$} \\
Perfusate & $3.65 \pm 0.95$ & $4.52 \pm 2.76$ \\
Bile & $2.05 \pm 1.16$ & $0.002 \pm 0.001$ \\
\hline
\end{tabular}

Livers were perfused with a medium containing Krebs/bicarbonate buffer supplied with $0.5 \%$ BSA in a recirculating system. During 30 min, bile was collected with 5-min intervals. In addition, samples were drawn from the perfusate every $5 \mathrm{~min}$. During this collection period, glutathione secretion into perfusate and bile were both linear with time. All given values are in GSH equivalents \pm SD. For details see Methods.

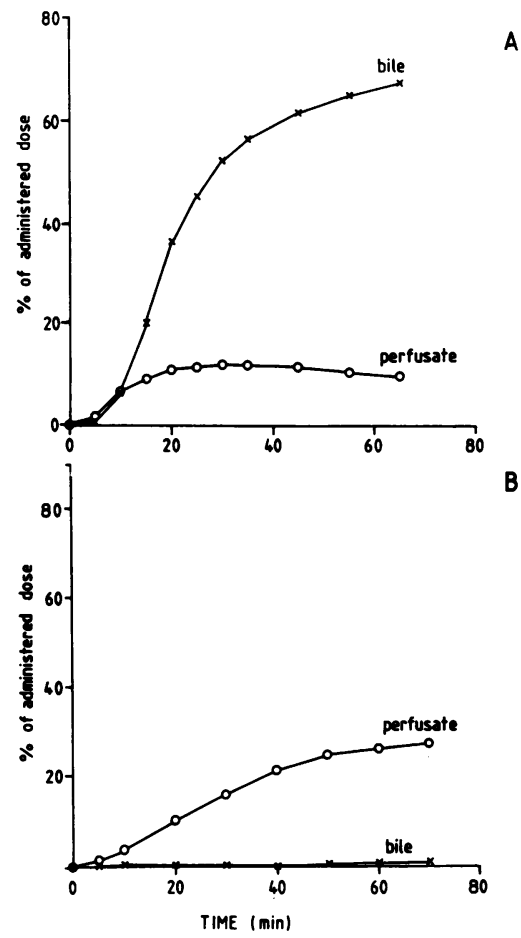

Figure 2. Secretion of GS-DNP in the isolated, perfused rat liver. After cannulation of the bile duct and isolation of the liver, CDNB was added to the recirculating perfusate $(100 \mathrm{ml})$ to a final concentration of $200 \mu \mathrm{M}$. GS-DNP concentrations were determined in bile and perfusate samples as described in Methods. $(A)$ normal liver; $(B) \mathrm{TR}^{-}$ mutant liver. $(x)$ cumulative GS-DNP secretion into bile; $O$, GSDNP in perfusate.

membrane. Average sinusoidal secretion in both types of liver amounted $\sim 29 \%$ of the administered dose (results not shown).

Secretion of GS-DNP by normal and mutant isolated hepatocytes. Because transport through the canalicular membrane appears to be faster than efflux over the sinusoidal membrane, it may be expected that efflux from isolated hepatocytes derived from normal rat liver represents predominantly canalicular transport. This route is blocked in $\mathrm{TR}^{-}$rat liver; therefore efflux from isolated hepatocytes from $\mathrm{TR}^{-}$rats is expected to represent only sinusoidal transport and should be slower. To test this hypothesis we isolated hepatocytes from livers of both strains.

Firstly we examined the velocity of conjugation of CDNB within the isolated hepatocyte. Cells were incubated with $\left[{ }^{14} \mathrm{C}\right] \mathrm{CDNB}$ and after $30 \mathrm{~s}$, the cells were separated from the medium. After $30 \mathrm{~s},>90 \%$ of the radioactivity had been taken up by the cells. Intracellular radioactivity was analyzed by thin-layer chromatography and as shown in Fig. 3, all intracellular radioactivity cochromatographed with a ${ }^{14} \mathrm{C}$-labeled GS-DNP standard. Identical results were obtained in $\mathrm{TR}^{-}$hepatocytes. Glutathione $S$-transferase activity in liver homogenates with CDNB as substrate was similar in both strains (results not shown). It is clear from this experiment that conjugation of CDNB is extremely rapid and completed within $30 \mathrm{~s}$.

Subsequently, the efflux of GS-DNP from isolated normal and mutant hepatocytes was measured. Fig. 4 shows two representative experiments. The cells $(10 \mathrm{mg}$ dry weight $/ \mathrm{ml})$ were incubated in Krebs/bicarbonate with $0.5 \%$ BSA and $100 \mu \mathrm{M}$ CDNB was added to the medium. After the indicated time period, samples were taken and centrifuged through a layer of silicone oil to separate cells from medium. In the experiment shown in Fig. $4 A$, efflux from control Wistar cells $\left(\mathrm{GT}^{+} \mathrm{TR}^{+}\right)$ was compared with that from transport-mutant $\left(\mathrm{GT}^{+} \mathrm{TR}^{-}\right)$ cells. In the figure, the amount of GS-DNP is depicted that is found in the medium after the indicated time. It is clear that 


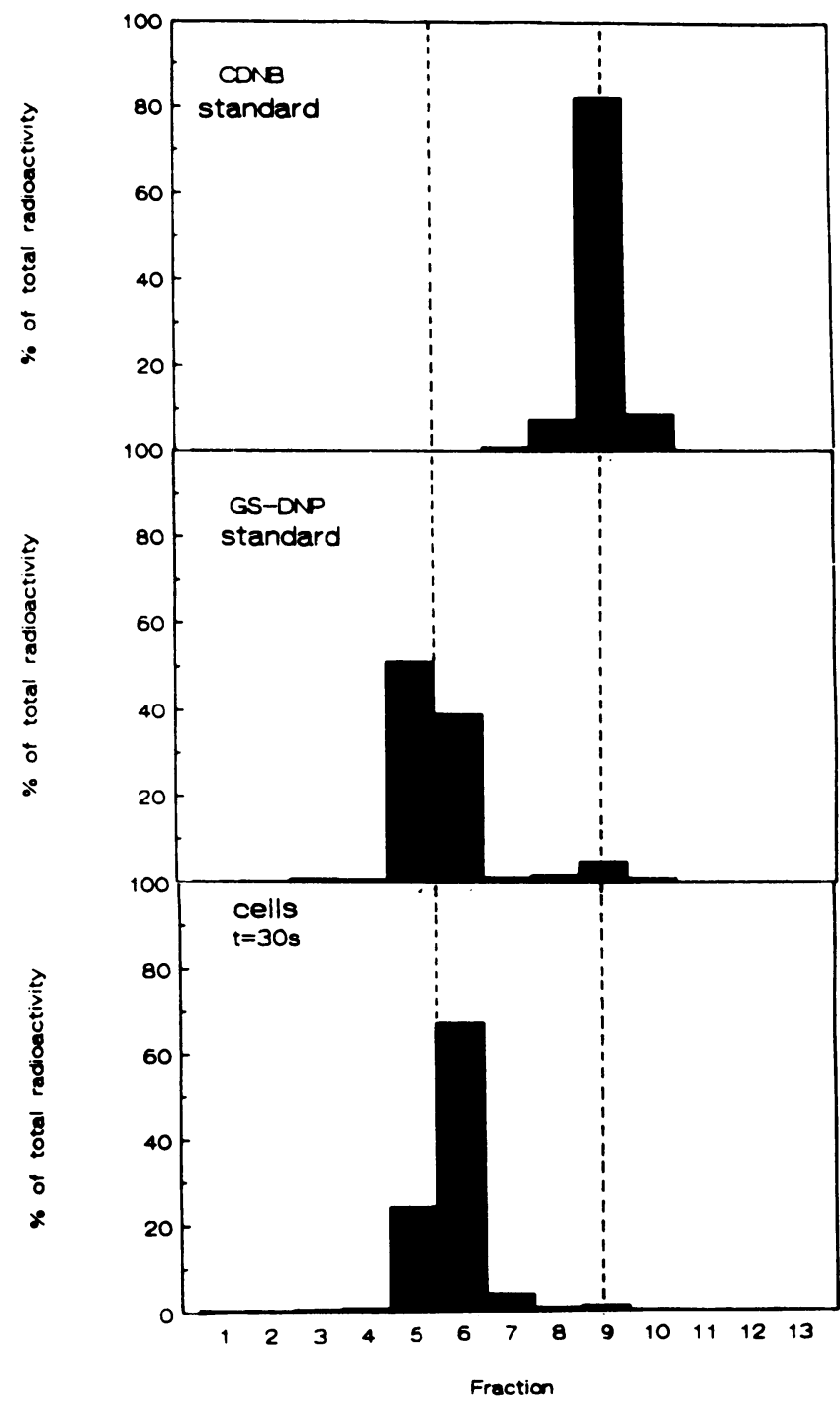

Figure 3. Analysis of intracellular metabolites of CDNB after addition to isolated hepatocytes. Hepatocytes $(10 \mathrm{mg}$ dry weight $/ \mathrm{ml})$ were incubated with $100 \mu \mathrm{M}\left[{ }^{14} \mathrm{C}\right] \mathrm{CDNB}$ and after $30 \mathrm{~s}$, the cells were separated from the medium by centrifugation through oil. The intracellular radioactivity was analyzed by TLC as described in Methods. Chromatographic behavior was compared with radioactive standards of CDNB and GS-DNP.

efflux from control cells is considerably faster than from mutant cells. Fig. $4 B$ shows that very similar results were obtained when glucuronyltransferase-deficient Gunn $\left(\mathrm{GT}^{-} \mathrm{TR}^{+}\right)$rat cells and double mutant $\left(\mathrm{GT}^{-} \mathrm{TR}^{-}\right)$cells were used, respectively. The latter hybrid strain of rats was obtained by crossing the Gunn rat $\left(\mathrm{GT}^{-}\right)$with the $\mathrm{TR}^{-}$mutant (3). The advantage of this double mutant rat is that bilirubin glucuronides do not accumulate in the liver, which could possibly interfere with transport of organic anions. The $\mathrm{GT}^{-} \mathrm{TR}^{-}$rat is a cleaner experimental model when compared with the $\mathrm{GT}^{-} \mathrm{TR}^{+}$rat: both rats have a high level of unconjugated bilirubin in their serum and liver.

The experiments of Fig. 4 only give a qualitative impression of the differences in efflux between normal and mutant rats. The time interval of measurement was too long to calculate the initial efflux rates in the two strains. This was, how-

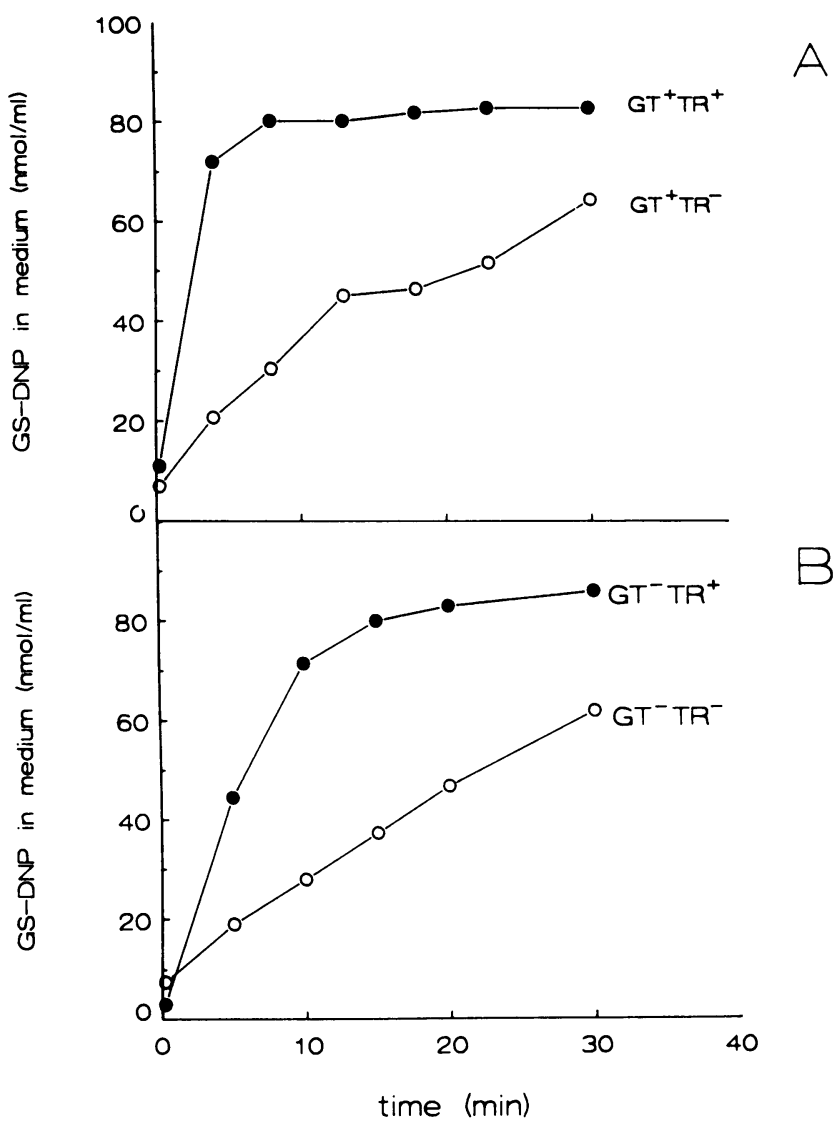

Figure 4. Secretion of GS-DNP by isolated hepatocytes from normal and mutant rats. Hepatocytes $(10 \mathrm{mg}$ dry weight $/ \mathrm{ml})$ were incubated with $100 \mu \mathrm{M}$ CDNB and after the indicated time periods, the cells were separated from the medium by centrifugation through oil. GSDNP concentrations were determined in the medium as described in Methods. $(A)$ Hepatocytes from Wistar $\left(\mathrm{GT}^{+} \mathrm{TR}^{+}\right)$and single mutant $\left(\mathrm{GT}^{+} \mathrm{TR}^{-}\right)$rats. $(B)$ Hepatocytes from Gunn $\left(\mathrm{GT}^{-} \mathrm{TR}^{+}\right)$and double mutant $\left(\mathrm{GT}^{-} \mathrm{TR}^{-}\right)$rats.

ever, done in a separate set of experiments with a number of different cell preparations, as shown in Table IV. In these experiments a standard assay was used in which the secretion of GS-DNP was measured from $30 \mathrm{~s}$ to $2.5 \mathrm{~min}$ after the addition of $100 \mu \mathrm{M}{ }^{14} \mathrm{C}$-labeled CDNB (Fig. 5). As described above, the conjugation of CDNB is completed within $30 \mathrm{~s}$.

Table IV. Initial Efflux Rates of GS-DNP from Normal and Mutant Hepatocytes

\begin{tabular}{llcl}
\hline \multicolumn{1}{c}{ Strain } & Code & GS-DNP efflux rate & $n$ \\
\hline & & $n$ mol/min $\cdot g d r y w t$ & \\
Wistar & & $839 \pm 346$ & 8 \\
Gunn & GT $^{+} \mathrm{TR}^{+}$ & $978 \pm 250$ & 5 \\
Single mutant & $\mathrm{GT}^{-} \mathrm{TR}^{+}$ & $185 \pm 81$ & 7 \\
Double mutant & $\mathrm{GT}^{+} \mathrm{TR}^{-}$ & $197 \pm 94$ & 5
\end{tabular}

Isolated hepatocytes were incubated with $100 \mu \mathrm{M}{ }^{14} \mathrm{C}-\mathrm{CDNB}$ and the efflux of GS-DNP was measured from $30 \mathrm{~s}$ to $2.5 \mathrm{~min}$ after addition of the substrate as described in Methods. 


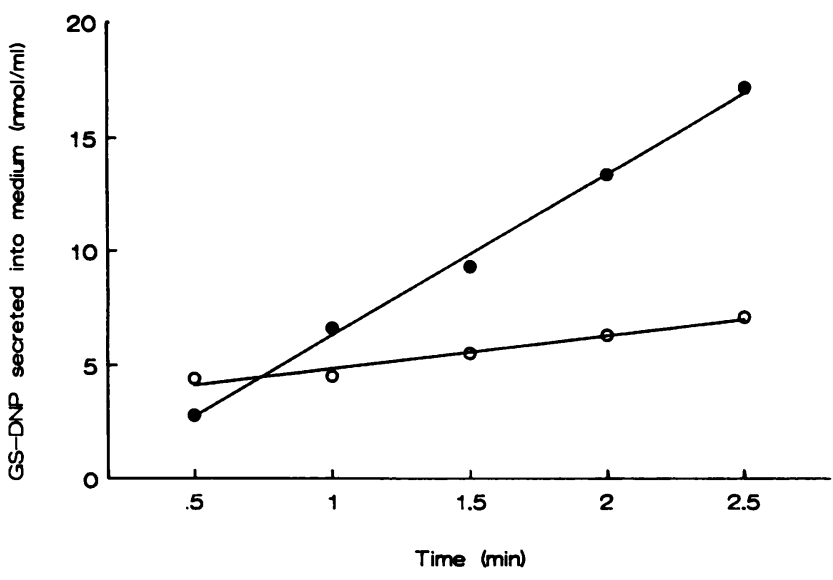

Figure 5. GS-DNP efflux from normal and mutant hepatocytes. Hepatocytes $(10 \mathrm{mg}$ dry weight $/ \mathrm{ml})$ were incubated with $100 \mu \mathrm{M}$

$\left[{ }^{14} \mathrm{C}\right] \mathrm{CDNB}$. Subsequently samples were drawn from the suspension at $30 \mathrm{~s}$ to $2.5 \mathrm{~min}$ after addition of $\mathrm{CDNB}$, cells were separated from medium and radioactivity was determined in the medium fraction. (Closed symbols) Normal $\left(\mathrm{GT}^{+} \mathrm{TR}^{+}\right.$) hepatocytes; (open symbols) mutant $\left(\mathrm{GT}^{+} \mathrm{TR}^{-}\right)$hepatocytes.

Thus, at the start of the efflux measurement all substrate is present intracellularly as GS-DNP. Furthermore, as is clear from Fig. 5, the secretion of GS-DNP was linear during this short time interval, indicating that an initial efflux rate was measured. The average efflux rates for the different cell preparations that were obtained with this method are listed in Table IV (Fig. 5 displays a representative example from this set of experiments). The efflux rates for $\mathrm{TR}^{-}$and $\mathrm{TR}^{+}$strains were significantly different $(P<0.005)$. On the other hand, GSDNP secretion from $\mathrm{GT}^{-} \mathrm{TR}^{+}$(Gunn) hepatocytes $(n=5)$ was not significantly different from that of normal Wistar hepatocytes.

At the end of these experiments, the cellular GSH concentration was determined and GSH depletion under these conditions was never $>50 \%$ of the initial level. In addition, under these experimental conditions no increased LDH leakage from the cells was observed.

The kinetic parameters for secretion of GS-DNP $\left(V_{\max }\right.$ and $K_{\mathrm{m}}$ ) from hepatocytes of Gunn rats and $\mathrm{GT}^{-} \mathrm{TR}^{-}$double mutants were subsequently determined. Hepatocytes were incubated with ${ }^{14} \mathrm{C}$-labeled CDNB, diluted with different amounts of unlabeled CDNB and the initial efflux rate of label from the cells was measured as described above. In separate but identical experiments the intracellular volume was determined for hepatocytes of both strains $\left(\mathrm{GT}^{-} \mathrm{TR}^{+}\right.$and $\left.\mathrm{GT}^{-} \mathrm{TR}^{-}\right)$. Because all CDNB is taken up by the cells and completely conjugated to GS-DNP, the intracellular concentration of GS-DNP at the start of the efflux measurement could be calculated (see Methods). Fig. 6 shows a double reciprocal plot of the relation between substrate concentration and initial secretion rate of GS-DNP. The $V_{\max }$ 's were 1,514 and $498 \mathrm{nmol} / \mathrm{min} \cdot \mathrm{g}$ dry weight in cells from Gunn $\left(\mathrm{GT}^{-} \mathrm{TR}^{+}\right)$rats and $\mathrm{GT}^{-} \mathrm{TR}^{-}$double mutants, respectively. The $K_{\mathrm{m}}$ 's were 0.92 and $3.3 \mathrm{mM}$ (intracellular GS-DNP) for cells from Gunn rats and the $\mathrm{GT}^{-} \mathrm{TR}^{-}$double mutants, respectively (average values from three experiments). Thus, the $V_{\max }$ of transport of GS-DNP from cell to medium is threefold reduced in hepatocytes from $\mathrm{GT}^{-} \mathrm{TR}^{-}$rats and the $K_{\mathrm{m}}$ is increased almost fourfold.

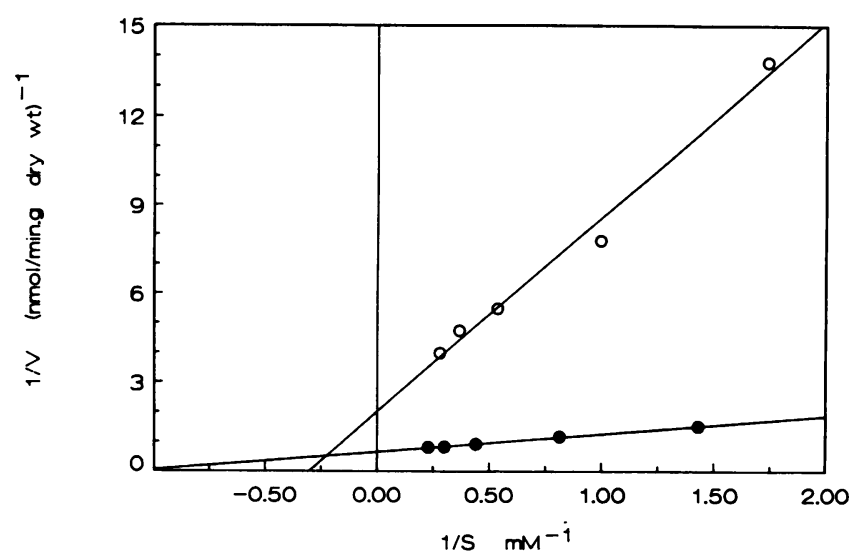

Figure 6. Double reciprocal plot of GS-DNP secretion rate versus intracellular GS-DNP concentration in isolated hepatocytes. Hepatocytes $(10 \mathrm{mg}$ dry weight $/ \mathrm{ml})$ were incubated with ${ }^{14} \mathrm{C}$-labeled CDNB $(0.1 \mu \mathrm{Ci} / \mathrm{ml})$ to which different amounts of unlabeled CDNB $(10-100 \mu \mathrm{M})$ were added. Secretion rates were measured by determination of the radioactivity in the supernatant of cell samples taken from $30 \mathrm{~s}$ to $2.5 \mathrm{~min}$ after addition of CDNB. On the abscissa the reciprocal value of the intracellular GS-DNP concentration in millimolar is given. (Closed symbols) Hepatocytes from $\mathrm{GT}^{-} \mathrm{TR}^{+}$(Gunn) rat liver; (open symbols) hepatocytes from double mutant $\mathrm{GT}^{-} \mathrm{TR}^{-}$rat liver.

GS-DNP secretion by isolated hepatocytes after preloading of the cells at reduced temperature. In the experiments described above, efflux of GS-DNP from hepatocytes was measured $30 \mathrm{~s}$ after incubation of the cells with CDNB. We have shown (Fig. 3) that within this time period a complete conjugation of the substrate to GS-DNP took place. This allows us to interpret the efflux of GS-DNP from the cells as an initial efflux rate. To validate this assay system further, we carried out an additional set of experiments in which we preloaded the cells with GS-DNP at reduced temperature. In the experiment of Fig. 7, the initial efflux rates of GS-DNP from the cells was measured at different temperatures. It is clear that the efflux is highly temperature dependent and completely inhibited

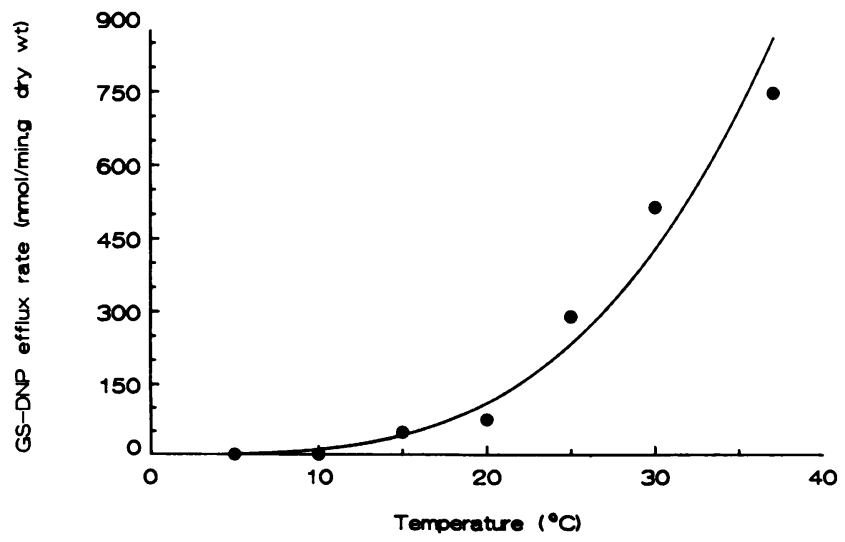

Figure 7. Temperature dependence of GS-DNP efflux from isolated hepatocytes. Normal isolated hepatocytes $(10 \mathrm{mg}$ dry weight $/ \mathrm{ml})$ were incubated with $100 \mu \mathrm{M}\left[{ }^{14} \mathrm{C}\right] \mathrm{CDNB}$ at $10^{\circ} \mathrm{C}$ for $15 \mathrm{~min}$. Subsequently the cells were diluted sixfold with medium of the indicated temperature and efflux of GS-DNP was measured from $30 \mathrm{~s}$ to 2.5 min after dilution as described in Methods. 
$<10^{\circ} \mathrm{C}$ (Fig. 7 is a representative experiment from a set of three and in all experiments the efflux rate at $10^{\circ} \mathrm{C}$ was zero). At all temperatures $>90 \%$ uptake of CDNB was observed. Analysis by thin-layer chromatography of intracellular metabolites formed after 10 min incubation of the cells with CDNB at $10^{\circ} \mathrm{C}$ revealed only GS-DNP. We used this phenomenon to preload the cells with the substrate. Hepatocytes were incubated at $10^{\circ} \mathrm{C}$ for $10 \mathrm{~min}$ in the presence of $\left[{ }^{14} \mathrm{C}\right] \mathrm{CDNB}$. After preloading, the cells were diluted 6-fold in medium of $37^{\circ} \mathrm{C}$ and efflux was measured from $30 \mathrm{~s}$ to $2.5 \mathrm{~min}$ after dilution. The results of this set of experiments is given in Table V. The initial efflux rates that were obtained with this method were not different from those described in Table IV.

\section{Discussion}

The data presented in this paper clearly demonstrate that the biliary secretion of glutathione and a glutathione-conjugate is severely impaired in mutant $\mathrm{TR}^{-}$rats. It has been shown previously that this rat is unable to secrete BSP (2), bilirubin glucuronides and DBSP $(3,4)$, cysteinyl-leukotrienes (23), and glucuronidated and sulfated bile acids (5). Thus, the biliary secretion of these compounds is similarly affected by the mutation. On the other hand cholate, taurocholate and the cation tributylmethyl ammonium are normally secreted into bile of the mutant rat and transport of the neutral steroid ouabain is only mildly reduced (4). We have not been able yet to demonstrate where the mutation in the $\mathrm{TR}^{-}$rat is located. The most comprehensible explanation for the experimental data so far obtained (see references $2-5$ and this paper) would be that the organic anion transport system in the canalicular plasma membrane is either not present or not functioning. If so, this putative transport system must have a very broad specificity as can be inferred from the spectrum of organic anions of which the hepatobiliary transport is impaired. On the other hand, it is possible that this system consists of a cluster of related transporting proteins that are all defective in the $\mathrm{TR}^{-}$rat, or that the mutation precludes proper functioning of this cluster of transporters.

Our experiments with isolated hepatocytes demonstrate that the defect of the $\mathrm{TR}^{-}$mutant rat is also expressed at the level of the isolated single cell. These results indicate that the defect lies within the cell and that extracellular mechanisms, like increased permeability of tight junctions, can be excluded as the cause of the defect. Theoretically, the defect in the mutant rat could also be caused by a redistribution of canalicular

Table V. Initial Eflux Rates of GS-DNP

from Normal and Mutant Hepatocytes

after Preloading the Cells at Reduced Temperature

\begin{tabular}{lccr}
\hline \multicolumn{1}{c}{ Strain } & Code & GS-DNP efflux rate & $n$ \\
\hline & & nmol/min $\cdot g d r y w t$ & \\
Wistar & $\mathrm{GT}^{+} \mathrm{TR}^{+}$ & $714 \pm 165$ & 4 \\
Single mutant & $\mathrm{GT}^{+} \mathrm{TR}^{-}$ & $141 \pm 60$ & 4 \\
\hline
\end{tabular}

Isolated hepatocytes were incubated with $100 \mu \mathrm{M}{ }^{14} \mathrm{C}-\mathrm{CDNB}$ for 10 min at $10^{\circ} \mathrm{C}$. Subsequently, the cells were diluted sixfold with medium of $37^{\circ} \mathrm{C}$ and the efflux of GS-DNP was measured from $30 \mathrm{~s}$ to $2.5 \mathrm{~min}$ after dilution as described in Methods. carrier molecules over the other plasma membrane domains of the hepatocyte as occurs after bile duct ligation (24). Our experiments with isolated hepatocytes also exclude this possibility.

Lindwall and Boyer (25) suggest that the secretion of GSDNP from hepatocytes in maintenance culture predominantly occurs via a canalicular transport system. Our results strongly support this concept. The data obtained with the isolated, perfused liver confirm that the secretion defect in the $\mathrm{TR}^{-}$rat liver is restricted to canalicular secretion. Sinusoidal efflux is normal. Therefore, the finding that efflux from isolated hepatocytes from $\mathrm{TR}^{-}$rat liver is significantly impaired confirms the assumption that GS-DNP efflux from isolated hepatocytes is mainly governed by canalicular transport pathways. Therefore, the residual efflux of GS-DNP from TR $^{-}$rat liver cells may predominantly represent sinusoidal pathways.

We have also measured the secretion of GSH from isolated normal and mutant hepatocytes. Although on basis of our findings with the isolated, perfused liver it might be expected that GSH secretion from mutant hepatocytes is slower than from normal hepatocytes, we did not find a significant difference. Two explanations can be given for this observation. Firstly, the sinusoidal secretion rate of GSH is higher than that into the canaliculus. Thus, GSH secretion from isolated hepatocytes mainly consists of sinusoidal secretion and the absence of canalicular secretion will have relatively little effect on the total GSH secretion. Secondly, the GSH concentration in liver (and isolated hepatocytes) of the $\mathrm{TR}^{-}$rat is significantly higher than in the control liver. Thus, secretion via the sinusoidal system in $\mathrm{TR}^{-}$hepatocytes may be higher than in control hepatocytes, thereby masking the absence of canalicular secretion.

That virtually no glutathione is found in bile from the TR rat does not necessarily mean that canalicular secretion of glutathione is completely absent. Several groups have shown that extensive hydrolysis of glutathione occurs in bile $(6,9,26$, 27). This hydrolysis is catalyzed by gamma-GT $(6,9)$. If this enzyme is saturated at glutathione concentrations found in normal bile, as has been suggested by Gregus et al. (9), a decrease in the biliary glutathione concentration will lead to relatively more hydrolysis and this effect will be enhanced by the lower bile flow in the mutant rat. This, however, can only partly explain the strong reduction in biliary concentration of glutathione that we observe. The decreased biliary glutathione concentration is accompanied by a decreased biliary glutamate concentration and an elevated intracellular glutathione concentration. This suggests that the mutation concerns a genuine secretion defect of GSH. The increased intracellular GSH concentration may not be solely due to accumulation of the tripeptide. Indirect factors like increased precursor amino acid availability may enhance the effect.

The elevated intracellular glutathione concentration in the mutant rat is not accompanied by a significantly increased sinusoidal secretion of glutathione in the isolated, perfused liver. This is in accordance with the observations of Ookhtens et al. (28) that under normal conditions, the sinusoidal secretion system is nearly saturated so that an increase in the intracellular GSH concentration will have a relatively small effect on the sinusoidal secretion rate. The GSH secretion rates that we find in the isolated perfused liver are, however, lower than those found in other studies $(28,29)$. We do not have a clear explanation for this, although our experiments have been per- 
formed with rats that were older $(>300 \mathrm{~g})$ and of a different strain (Wistar vs. Sprague-Dawley).

Ballatori et al. $(6,30)$ found that injection of BSP in rats decreases the concentration of glutamate in bile, which is derived from glutathione. However, they also observed an unexplained effect of BSP on the secretion of a number of other amino acids, like phenylalanine, tyrosine, and the branchedchain amino acids, which are not involved in glutathione metabolism. This is in agreement with our observations that the secretion of a number of amino acids is reduced in the $\mathrm{TR}^{-}$rat. We propose that these amino acids are partly secreted into bile via the affected transport system. The effect of the mutation on amino acid secretion is, however, relatively small (two to threefold reduction in biliary concentration) compared with the reduction in transport of compounds like dinitrophenylglutathione ( $>10$-fold, see Fig. 1) and bilirubin diglucuronide (10-fold) (3). This may indicate that the affected transport system is not the only transport system through which amino acids can be secreted into bile.

\section{Acknowledgments}

We thank Dr. Bert Groen, Dr. Peter Meier (Division of Clinical Pharmacology, University Hospital, Zurich), and Dr. Theo Akerboom (Institute of Physiological Chemistry, University of Dusseldorf) for helpful discussions; Peter Plomp and George van Woerkom for assistance with the isolation of hepatocytes; and Truus Klebach for preparation of the manuscript.

Maintenance of the animal colony was supported in part by MEDIGON (Foundation for Medical and Health Research) and the Royal Netherlands Veterinary Association.

\section{References}

1. Jansen, P. L. M., and R. P. J. Oude Elferink. 1988. Hereditary hyperbilirubinemias: a molecular and mechanistic approach. Semin. Liver Dis. 8:168-178.

2. Jansen, P. L. M., W. H. Peters, and W. H. Lamers. 1985. Hereditary chronic conjugated hyperbilirubinemia in mutant rats caused by defective hepatic anion transport. Hepatology (Baltimore). 5:573-579.

3. Jansen, P. L. M., W. H. M. Peters, and D. K. F. Meijer. 1987. Hepatobiliary secretion of organic anions in double mutant rats with a combination of defective canalicular transport and uridine 5'-diphosphate-glucuronyl-transferase deficiency. Gastroenterology. 93:10941103.

4. Jansen, P. L. M., G. M. M. Groothuis, W. H. M. Peters, and D. K. F. Meijer. 1987. Selective hepatobiliary transport defect for organic anions and neutral steroids in mutant rats with hereditary conjugated hyperbilirubinemia. Hepatology (Baltimore). 7:71-76.

5. Oude Elferink, R. P. J., J. de Haan, K. Lambert, A. F. Hofmann, and P. L. M. Jansen. 1987. Metabolism and biliary secretion of nordeoxycholate in normal and mutant rats. Evidence for separate excretory pathways for unconjugated and conjugated bile acids. Hepatology (Baltimore). 7:1109. (Abstr.)

6. Ballatori, N., R. Jacob, and J. L. Boyer. 1986. Intrabiliary glutathione hydrolysis. A source of glutamate in bile. J. Biol. Chem. 261:7860-7865.

7. Lauterburg, B. H., C. V. Smith, H. Hughes, and J. R. Mitchell. 1984. Biliary secretion of glutathione and glutathione disulfide in the rat. Regulation and response to oxidative stress. J. Clin. Invest. 73:124-133.

8. Eberle, D., R. Clarke, and N. Kaplowitz. 1981. Rapid oxidation in vitro of endogenous and exogenous glutathione in bile of rats. $J$. Biol. Chem. 256:2115-2117.

9. Gregus, Z., A. F. Stein, and C. D. Klaassen. 1987. Effect of inhibition of gamma-glutamyltranspeptidase on biliary and urinary secretion of glutathione-derived thiols and methylmercury. J. Pharmacol. Exp. Ther. 242:27-32.

10. Inoue, M., T. Akerboom, H. Sies, R. Kinne, T. Tran, and I. M. Arias. 1984. Biliary transport of glutathione S-conjugate by rat liver canalicular membrane vesicles. J. Biol. Chem. 259:4990-5002.

11. Akerboom, T. P. M., M. Bilzer, and H. Sies. 1982. Competition between transport of glutathione disulfide (GSSG) and glutathione S-conjugates from perfused rat liver into bile. FEBS (Fed. Eur. Biochem. Soc.) Lett. 140:73-76.

12. Habig, W. H., and W. B. Jakoby. 1981. Assays for differentiation of glutathione S-transferases. Methods Enzymol. 77:398-405.

13. Awasthi, Y. C., H. S. Garg, D. D. Dao, C. A. Partridge, S. K. Srivastave. 1981. Enzymatic conjugation of erythrocyte glutathione with 1-chloro-2,4-dinitrobenzene: the fate of glutathione conjugate in erythrocytes and the effect of glutathione depletion on hemoglobin. Blood. 58:733-738.

14. Meijer, D. K. F., K. Keulemans, and G. J. Mulder. 1981. Isolated perfused rat liver technique. Methods Enzymol. 77:81-94.

15. Berry, N. M., and D. S. Friend. 1969. High-yield preparation of isolated rat parenchymal cells. J. Cell Biol. 43:506-520.

16. Tietze, F. 1969. Enzymic method for quantitative determination of nanogram amounts of total and oxidized glutathione: application to mammalian blood and other tissues. Anal. Biochem. 27:502522.

17. Sacchetta, P., D. DiCola, and G. Federici. 1986. Alkaline hydrolysis of N-ethylmaleimide allows a rapid assay of glutathione disulfide in biological samples. Anal. Biochem. 154:205-208.

18. Habig, W. H., and W. B. Jakoby. 1981. Assays for differentiation of glutathione S-transferases. Methods Enzymol. 77:398-405.

19. Szasz, G. 1982. Gamma-glutamyltranspeptidase. In Methods of Enzymatic Analysis. Vol. 2. H. U. Bergmeyer, editor. Academic Press, Inc., New York. 715-720.

20. Wahllander, A., and H. Sies. 1979. Glutathione S-conjugate formation from 1-chloro-2,4-dinitrobenzene and biliary S-conjugate secretion if the perfused rat liver. Eur. J. Biochem. 96:441-446.

21. Inoue, M., R. Kinne, T. Tran, L. Biempica, and I. M. Arias. 1983. Rat liver canalicular membrane vesicles. J. Biol. Chem. 258:5183-5188.

22. Ding, J. L., G. D. Smith, and T. J. Peters. 1981. Purification and properties of gamma-glutamyl transferase from normal rat liver. Biochim. Biophys. Acta. 857:334-343.

23. Huber, M., A. Guhlmann, P. L. M. Jansen, and D. Keppler. 1987. Hereditary defect of hepatobiliary cysteinyl leukotriene elimination in mutant rats with defective hepatic anion secretion. Hepatology (Baltimore). 7:224-228.

24. Durand-Schneider, A. M., M. Maurice, M. Dumont, and G. Feldmann. 1987. Effect of colchicine and phalloidin on the redistribution of three plasma membrane antigens in rat hepatocytes: comparison with bile duct ligation. Hepatology (Baltimore). 7:1239-1248.

25. Lindwall, G., and T. D. Boyer. 1987. Secretion of glutathione conjugates by primary cultured rat hepatocytes. J. Biol. Chem. 262:5151-5158.

26. Gregus, Z., A. F. Stein, and C. D. Klaassen. 1987. Age-dependent biliary secretion of glutathione-related thiols in rats: role of gamma-glutamyltransferase. Am. J. Physiol. 253:G86-G92.

27. Abbot, W. A., and A. Meister. 1986. Intrahepatic transport and utilization of biliary glutathione and its metabolites. Proc. Natl. Acad. Sci. USA. 83:1246-1250.

28. Ookhtens, M., K. Hobdy, M. C. Corvasce, T. Yee Aw, and N. Kaplowitz. 1985. Sinusoidal efflux of glutathione in the perfused rat liver. J. Clin. Invest. 75:258-265.

29. Lauterburg, B. H., J. D. Adams, and J. R. Mitchell. 1984. Hepatic glutathione homeostasis in the rat: efflux accounts for glutathione turnover. Hepatology (Baltimore). 4:586-590.

30. Ballatori, N., and T. W. Clarkson. 1985. Sulfobromophtalein inhibition of glutathione and methylmercury secretion into bile. $\mathrm{Am}$. J. Physiol. 248:G238-G245. 